\title{
Management of Acute Diarrhea: From Evidence to Policy
}

\author{
Shinjini Bhatnagar, Seema AlaM* and Piyush Gupta* \\ National Co-ordinator, and *Joint National Co-ordinators, IAP-UNICEF Program on Evidence-based Management of Diarrhea. \\ Correspondence to: Dr Shinjini Bhatnagar, Center for Diarrheal and Nutrition Research, Department of Pediatrics, All India \\ Institute of Medical Sciences, Delhi110029, India.shinjinibhatnagar@gmail.com
}

$\mathrm{D}$ iarrhea remains an important contributor to childhood deaths in India, being one of the top 10 causes of deaths among infants and children of 0 4 year of age. About $10 \%$ of infants and $14 \%$ of $0-4$ year children die due to diarrhea in India(1). Important interventions for reducing mortality due to childhood diarrhea include (i) appropriate diarrhea management; and (ii) promotion of personal and household hygiene practices. Two effective interventions have been introduced as part of the diarrhea management in the last two decades, namely low osmolarity ORS and zinc.

\section{New TeChNical Advances: Low OSMOlarity ORS AND ZINC}

The WHO Meeting of Experts concluded in 2001 that there are programmatic advantages of using a single rehydrating solution globally for all causes of diarrhea in all ages. Evidence from large, well conducted, randomized controlled trials including those in India, showed that low osmolarity ORS with $75 \mathrm{mEq} / \mathrm{L}$ of sodium and $75 \mathrm{mmol} / \mathrm{L}$ of glucose, osmolarity of $245 \mathrm{osmol} / \mathrm{L}$ is effective in children with non cholera diarrhea and in adults and children with cholera(2). This new improved ORS was recommended by the WHO/UNICEF as the universal solution for all ages and all types of diarrhea(3). It was also included in the national policy by the Government of India in 2004. Subsequently, two Phase IV studies on more than 100,000 adults and children hospitalized with diarrhea (approximately 20\% with cholera), reported no increased risk of symptomatic hyponatremia with low osmolarity ORS(4).
A number of trials in India and other low middle income countries have documented faster recovery and reduced severity from zinc supplementation during acute diarrhea $(5,6)$. Zinc deficiency is common in children living in such settings due to low intake of animal foods, high dietary phytate content, and overall inadequate diets(7). This led to the WHO recommendation of supplemental zinc syrup or tablets $(10 \mathrm{mg}$ elemental zinc for infants $<6$ months and $20 \mathrm{mg}$ /day for children $\geq 6$ months for 10 to 14 days) during acute diarrhea(8). Addition of zinc to current case management strategy was evaluated in a cluster randomized study in six primary health centers in North India(9). Prevalence and hospitalization for diarrhea decreased significantly in the villages that received low osmolarity ORS and zinc as compared to the control villages. It is important to note that the prescriptions for antibiotics by care providers and use of unwarranted injections were significantly less, and the ORS use rates significantly higher in the intervention villages. Additionally, zinc given during an episode of diarrhea reduced subsequent diarrheal morbidity. Similar benefits on reduction of antibiotic use during diarrhea were seen in a large multicentre study done across India, Brazil, Ethiopia, Egypt, and the Philippines(10). Prompted by these results, Government of India included zinc in the National program for treatment of diarrhea in 2007.

\section{REVISED GUIDELINES FOR MANAGEMENT OF DiARRHEA}

The revised guidelines for management of diarrhea (personal communication) issued by the 
Government of India and the Indian Academy of Pediatrics recommend low osmolarity ORS, zinc (10 mg elemental zinc for infants 2 to 6 months and $20 \mathrm{mg} /$ day for children $\geq 6$ months for 14 days) and continued feeding of energy dense feeds in addition to breastfeeding(11). The guidelines emphasize the importance of home available fluids, hand washing and other hygiene practices. Antimicrobials are recommended only for gross blood in stools or Shigella positive culture, cholera, associated systemic infection, or severe malnutrition.

There is presently not enough evidence on either safety or efficacy of antisecretory drugs like racecadotril for its routine use in the treatment of diarrhea. There is no data from our settings. Methodology of most of the published studies on anti secretory drugs is questionable.

There is presently insufficient evidence to recommend probiotics in the treatment of acute diarrhea in our settings as almost all the studies till date are from developed countries. It is not possible to extrapolate the findings of these studies to our setting where the breastfeeding rates are higher and the microbial colonization of the gut is different. The effect of probiotics is strain related and there is paucity of data to establish the efficacy of the probiotics available in the Indian market. To recommend a particular species, it will have to be first evaluated in randomized controlled trials in Indian children. More clarity is required on strain standardization, their colonization, dose and duration of therapy, and interaction with other therapy (zinc) before probiotics can be considered for use during diarrhea in India.

\section{Challenges Ahead}

The current challenge in the diarrhea treatment program is an universal and more optimal application of the diarrhea management guidelines. Data from the National Family Health Survey (NFHS-3)(12) show that the ORS use rates have not changed in the last two decades; $18 \%$ in 1992-93 and $27 \%$ in 2005 . The cause for concern is that the ORS rates continue to be below $20 \%$ for states of Jharkand, UP, Nagaland, Assam and Rajasthan. Additionally, only about $43 \%$ Indian children suffering from diarrhea receive any oral rehydration therapy (ORT).

What is more alarming is that not more than $47 \%$ of prescriptions for diarrhea included ORS in a recent UNICEF survey of 10 Indian districts; while "tonics", anti-diarrheal drugs and injections continued to be prescribed in the same proportion as for ORS(13). Although Government of India has initiated provision of zinc in addition to low osmolarity ORS through public health system under the National Rural Health Mission, the survey documented less than $1 \%$ of prescriptions for zinc. One of the main reasons for this is lack of knowledge and awareness amongst care providers on how to implement existing cost-effective interventions. The challenge is to achieve greater coverage of these interventions in low-resource settings.

\section{IAP-UNICEF PROJECT TO IMPROVE EVIDENCE Based Management OF Diarrhea by Promoting Use OF Low OSMOLARITy ORS AND ZINC}

IAP and UNICEF initiated a nationwide program in 2009 to promote rational diarrhea management among medical colleges, health providers across 8 states of the country, with specific focus in 32 districts with poor health indices. The aim is to improve case management of diarrhea in the targeted areas by increasing awareness amongst health providers through workshops conducted by trained pediatricians and physicians from the same area.

The on-going program that started in September 2009 is being conducted over three phases. In the initial phase, the IAP National Consultative Group prepared a training capsule on evidence based management of diarrhea in the form of power point presentations, posters (see pages 214, 290) and videos. This was followed by a National Training of Trainers meeting to train the Zonal and State Coordinators. Three zonal workshops for Heads of the Departments of Pediatrics of medical colleges from South, North, and East Zone at Chennai, Delhi, and Kolkata, were concluded in Phase 2. In addition, State workshops were held at Uttarakhand, 
Chhattisgarh, Madhya Pradesh, Bihar, Odisha, Rajasthan, Uttar Pradesh and Jharkhand. Phase 3 will be initiated in March this year when 32 district level workshops will be conducted in the above mentioned eight states.

This program reaffirms the Indian Academy of Pediatrics commitment to find solutions for the rational management of diarrhea, a disease that continues to affect millions of children in the developing world.

Funding: UNICEF, India.

Competing interest: None stated.

\section{REFERENCES}

1. Report on Causes of Death: 2001-03, Office of Registrar General, India.

2. Hahn S, Kim Y, Garner P. Reduced osmolarity oral rehydration solution for treating dehydration due to diarrhoea in children: systematic review. BMJ 2001; 323: 81-85.

3. World Health Organization. Reduced osmolarity oral rehydration salts (ORS) formulation - Report from a meeting of experts jointly organized by UNICEF and WHO (WHO/FCH/CAH/01.22), New York, 18 July 2001. Available at: http:// www.who.int/child_adolescent_health/en/. Accessed 1 March, 2010.

4. Alam NH, Yunus M, Faruque ASG, Gyr N, Sattar $\mathrm{S}$, Parvin $\mathrm{S}$, et al. Symptomatic hyponatremia during treatment of dehydrating diarrheal disease with reduced osmolarity oral rehydration solution. JAMA 2006; 296: 567-573.

5. Bhutta ZA, Bird SM, Black RE, Brown KH, Gardner JM, Hidayat A, et al. Therapeutic effects of oral zinc in acute and persistent diarrhea in children in developing countries: pooled analysis of randomized controlled trials. Am J Clin Nutr 2000; 72: 1516-1522.

6. Bhatnagar S, Bahl R, Sharma PK, Kumar GT, Saxena SK, Bhan MK. Zinc with oral rehydration therapy reduces stool output and duration of diarrhea in hospitalized children: a randomized controlled trial. J Pediatr Gastroenterol Nutr 2004; 38: 34-40.

7. Walsh CT, Sandstead HH, Prasad AS, Newberne PM, Fraker PJ. Zinc: health effects and research priorities for the 1990s. Environ Health Perspect 1994; 102 Suppl 2: 5-46.

8. Fontaine O. Effect of zinc supplementation on clinical course of acute diarrhoea. J Health Popul Nutr 2001; 19: 339-346.

9. Bhandari N, Mazumder S, Taneja S, Dube B, Agarwal RC, Mahalanabis D, et al. Effectiveness of zinc supplementation plus oral rehydration salts compared with oral rehydration salts alone as a treatment for acute diarrhea in a primary care setting: a cluster randomized trial. Pediatrics 2008; 121: e1279-1285.

10. Awasthi S. Zinc supplementation in acute diarrhea is acceptable, does not interfere with oral rehydration, and reduces the use of other medications: a randomized trial in five countries. $\mathrm{J}$ Pediatr Gastroenterol Nutr 2006; 42: 300-305.

11. Bhatnagar S, Lodha R, Choudhury P, Sachdev HP, Shah $\mathrm{N}$, Narayan $\mathrm{S}$, Wadhwa $\mathrm{N}$, et al. IAP Guidelines 2006 on management of acute diarrhea. Indian Pediatr 2007; 44: 380-389.

12. National Family Health Survey (NFHS-3) India, 2005-6. Available at: http://www.nfhsindia.org/ nfhs3.html. Accessed March 1, 2010.

13. Management practices for childhood diarrhea in India. Survey of 10 districts. New Delhi: UNICEF; 2009. 